Journal of Applied Pharmaceutical Science Vol. 2 (10), pp. 01-010, October, 2012

Available online at http://www.japsonline.com

DOI: $10.7324 / \mathrm{JAPS} .2012 .21001$

ISSN 2231-3354 (cc) BY-NC-SA

\title{
Polysaccharides of the red algae "Pterocladia" growing on the Lebanese coast: Isolation, structural features with antioxidant and anticoagulant activities
}

\author{
C. Sebaaly ${ }^{1}$, N. Karaki ${ }^{1}$, N. Chahine ${ }^{2}$, A. Evidente ${ }^{3}$, A. yassine ${ }^{1}$, J. Habib ${ }^{1}$ and H. Kanaan ${ }^{1 *}$ \\ ${ }^{1}$ Laboratory of Biotechnology of Natural Substances and Health Products, Faculty of Pharmacy, Lebanese University, Beirut, Lebanon \\ ${ }^{2}$ Laboratory of Physiology, Faculty of Medicine, Lebanese University, Beirut, Lebanon \\ ${ }^{3}$ UNINA- Napoli-Italy.
}

\section{ARTICLE INFO}

Article history:

Received on: 25/09/2012

Revised on: 10/10/2012

Accepted on: 19/10/2012

Available online: $28 / 10 / 2012$

Key words:

Antioxidant,

anticoagulant activities,

carrageenans,

NMR and Infra-Red

Spectroscopy, red algae,

sulfated galactans

\begin{abstract}
In addition to their high nutritional value, red algae are of great interest as a source of therapeutic substances. However, despite their abundance on the Lebanese coast red algae have never been studied before. Therefore, we attempted to study among the available biomass one of the species of red algae growing on the Lebanese coast "Pterocladia". We performed the extraction of trace elements, fatty acids, sulfated galactans and watersoluble polysaccharides of the phycocolloids family (carrageenans) whose physicochemical gelling or stabilizing effects attract many industrial sectors. The analysis of trace elements shows large amounts of potassium, calcium, silicon and iron. Moreover, Pterocladia appears to be rich in saturated fatty acids (69\%) with palmitic acid as major fatty acid and $31 \%$ of monounsaturated fatty acids. The extraction yields were $2.7 \%$ for sulfated galactans and $11.5 \%$ for carrageenan. In order to elucidate their structures, $\mathrm{H}^{1} \mathrm{NMR}$ spectroscopy was performed as well as Infra-Red spectroscopy which allowed us to reveal their functional groups. A study of the antioxidant effect by the electrolysis method showed a greater effect for sulfated galactans. Furthermore, the study of the anticoagulant effect by APTT test, activated partial thromboplastin time, showed more pronounced anticoagulant power of sulfated galactans. The results of the present study confirmed the potential use of the red algae Pterocladia as a source of active known molecules.
\end{abstract}

\section{INTRODUCTION}

Seaweeds have been widely used by coastal populations for thousands of years owing to their high nutritional values (MacArtain et al., 2007). They are found to be very rich sources of food, feed, medicines and energy. Moreover, marine algae are the only sources for industrially important phycocolloids like agar, carrageenan and alginate. They have a lot of applications as stabilizer, viscosifier, gelling and emulsifying agents (Delattre $e t$ al., 2011). Apart from industrial uses, in recent years, polysaccharides of plant origin have emerged as an important class of bioactive natural products (Shanmugam et al., 2000).

\footnotetext{
* Corresponding Author

Pr. Hussein Kanaan. Faculty of Pharmacy, Lebanese University, Campus Hadath, Beirut, Lebanon. Tel: +961 3703532
}

Thus, medical and pharmaceutical industries are also interested since marine plants have proven to be rich sources of structurally diverse bioactive compounds with valuable pharmaceutical and biomedical potential (Pérez, 1997; Madhusudan et al., 2011). Indeed, the complex polysaccharides from red algae especially sulfated galactans and carrageenans defined as polymers of galactose possess broad spectrum therapeutic properties. They are reported to exhibit blood anticoagulant (Farias et al., 2000; Melo et al., 2004; Cumashi et al., 2007), immunomodulating, antitumor (Yuan et al., 2006), antiviral (Trinchero et al., 2009) and antioxidant activities (Yuan et al., 2006; Costa et al., 2010). In fact, red seaweed galactan sulfates are linear polysaccharides with alternating 3-linked $\beta$-D-galactopyranose units and 4-linked 3,6anhydro- $\alpha$-galactopyranose or $\alpha$-galactopyranose units (Cosson et 
al., 1995), having different positions and degrees of sulfation. Othersubstituents, as methyl ethers, pyruvic acid ketals, and single stubs of $\beta$-D-xylopyranose and/or other monosaccharides are sometimes present (Estevez et al., 2004). They have been divided in carrageenans, when the 4- linked residues are on the Dconfiguration (1,3-linked $\beta$-D-galactose and 1,4-linked $\alpha$-Dgalactose), and in agars, when these residues belong to the L-series (Estevez et al., 2004; Delattre et al., 2011). So in this context, the identification of natural and original polysaccharidic structures constitutes a new field of applications.

Red algae of the genus Pterocladia are used for industrial production of gelling galactans and are commonly distributed in the seas of Lebanon, Egypt, Brazil, Italy and other countries (Wassef et al., 2002; Silva et al., 2010; Bottalico et al., 2008). Previous researches have discussed the composition and the properties of polysaccharides from the red algae Pterocladia capillacea.

According to Whitfield et al (1999), the total amount of bromophenol from this species of red algae collected from eastern Australia was about $2590 \mathrm{ng} / \mathrm{g}$. Their nutritional properties, their amino and fatty acid profiles were also identified (Wassef et al., 2002). On the other hand, the study of Guven et al (1982) shows that this species has anticoagulant activity and the active compound was identified as a polypeptide. As well, the study of Silva et al (2010) shows that lectin from the marine alga Pterocladiella capillacea has peripheral actions with both antiinflammatory and antinociceptive properties and this by significantly reducing the migration of neutrophils, thereby inhibiting inflammatory mediators.

Nevertheless, despite their abundance on the Lebanese coast red seaweed have never been studied before. Therefore, we attempted to study among the available biomass one of the species of the red algae growing on the Lebanese coast "Pterocladia". We view that the potential of polysaccharides extracted from seaweed is antiviral, antioxidant and anticoagulant, which makes them agents of considerable interest; considering the immense biomedical prospects of sulfated polysaccharides, the profound and emerging functional properties published in recent times will be discussed here with experimental evidences. Thus, this paper describes the isolation, structural features, the antioxidant and anticoagulant activities of sulfated galactans and carrageenans present in the red seaweed Pterocladia grown on the Lebanese coast.

\section{MATERIALS AND METHODS}

Isolation and structural analysis of the polysaccharides from the red algae Pterocladia

Extraction of Sulfated Galactans

All The chemicals were purchased from Sigma AldrichLebanon. The marine red algae Pterocladia was collected at Rawché beach, Lebanon, separated from other species and sundried. The extraction was carried out by the method of Farias et al. (2000). The dried tissue ( $25 \mathrm{~g}$ ) was cut in small pieces, suspended in $250 \mathrm{ml}$ of $0.1 \mathrm{M}$ sodium acetate buffer ( $\mathrm{pH} 6.0$ ) containing 510 $\mathrm{mg}$ of papain (Sigma-Aldrich, Switzerland), $5 \mathrm{mM}$ EDTA and 5 $\mathrm{mM}$ cysteine, and incubated at $60^{\circ} \mathrm{C}$ for $24 \mathrm{~h}$. The incubation mixture was then filtered and the supernatant saved. The residue was washed with $138 \mathrm{ml}$ of distilled water, filtered again, and the two supernatants were combined. Sulfated polysaccharides in solution were precipitated with $16 \mathrm{ml}$ of $10 \%$ cetylpyridinium chloride solution. After standing at room temperature for $24 \mathrm{~h}$, the mixture was centrifuged at $2560 \mathrm{x} \mathrm{g}$, for $20 \mathrm{~min}$, at $5^{\circ} \mathrm{C}$. The sulfated polysaccharides in the pellet were washed with $610 \mathrm{ml}$ of $0.05 \%$ cetylpyridinium chloride solution, dissolved with $172 \mathrm{ml}$ of a $2 \mathrm{M} \mathrm{NaCl}$, ethanol (100:15, v/v) solution, and precipitated with $305 \mathrm{ml}$ of absolute ethanol. After $24 \mathrm{~h}$ at $4^{\circ} \mathrm{C}$, the precipitate was collected by centrifugation $\left(2560 \mathrm{x} \mathrm{g}\right.$ for $20 \mathrm{~min}$ at $\left.5^{\circ} \mathrm{C}\right)$, washed twice with $305 \mathrm{ml}$ of $80 \%$ ethanol, and once with the same volume of absolute ethanol. The final precipitate was dried at room temperature overnight and $660 \mathrm{mg}$ (dry weight) of crude polysaccharide were obtained after these procedures.

\section{Extraction and purification of carrageenans}

After washing with water to remove all possible impurities such as salt, sand, shells... samples were grinded to optimize the contact between the samples and solvents at various subsequent operations. They were then submitted to depigmentation: algae were treated with acetone overnight stirring, decant and filter to extract the hydrophobic pigments (chlorophylls and carotenoids), and with $80 \%$ ethanol by heating to reflux for 1 hour, filter then treat them with absolute ethanol to extract the hydrophilic pigments. View that carrageenan compounds are very soluble in water, this property is used for their extraction. $20 \mathrm{~g}$ of algae pretreated were heated in $200 \mathrm{ml}$ of water at a slightly alkaline $\mathrm{pH}(8-9)\left(0.5 \mathrm{M} \mathrm{NaHCO}_{3}\right.$ solution) in a water bath at $90^{\circ} \mathrm{C}$ for $3 \mathrm{~h}$. This is the $\mathrm{pH}$ where carrageenans are assumed to be stable. Then the mix was filtered in order to remove insoluble residues (cellulose), a viscous solution containing carrageenans was obtained and submitted to purification. This latter step is based on the ability of carrageenan to form a precipitate in the presence of excess alcohol or in a $\mathrm{KCl}$ solution. Therefore, a double volume of alcohol was added to the solution of carrageenan by stirring with a glass rod allowing the formation of a whitish filament carrageenan insoluble in alcohol. The carrageenan was washed with ethanol and was dried at room temperature for $24 \mathrm{~h}$, then pulverized, reduced to powder in a mortar and finally sieved. This process allowed us to obtain $2.3 \mathrm{~g}$ of carrageenan powder.

\section{${ }^{1} \mathrm{H}$ NMR spectroscopy}

About $3 \mathrm{mg}$ of each sample (carrageenan or sulfated galactans) were dissolved in $0.5 \mathrm{ml}$ of $99 \% \mathrm{D}_{2} \mathrm{O}$. All ${ }^{1} \mathrm{H}$ NMR spectra were recorded at $27^{\circ} \mathrm{C}$ on an "Ultrashield 300 Bruker" spectrometer operating at a frequency of $300 \mathrm{MHz}$ with an acquisition time of $5.29 \mathrm{~s}$, a pulse duration of $11 \mu \mathrm{s}$. All chemical shifts were expressed in ppm and reported relative to an internal tetra-methyl silane reference. 


\section{Infrared spectroscopy}

The infrared spectra were recorded on a "JASCO FT-IR 6300 " spectrometer for a range of frequencies between 400 and $4000 \mathrm{~cm}^{-1}$. The resolution was $4 \mathrm{~cm}^{-1}$. All samples were analyzed as $\mathrm{KBr}$ pellet.

\section{Determination of fatty acids from Pterocladia}

The following test was performed in the institute of Monocrystals, Kharkov, Ukraine. Approximately $1.2 \mathrm{~g}$ of dry algae Pterocladia previously grounded into particles of $0.5 \mathrm{~mm}$ was extracted with methanol-chloroform in portions of $10 \mathrm{ml}$ three times for 3 hours. The mix was filtered through the paper filter into a $10 \mathrm{ml}$ flask. $1 \mathrm{~g}$ of anhydrous sodium sulfate was added to the extract obtained, which was evaporated at $60^{\circ} \mathrm{C}$ in the nitrogen stream until dryness (a residue of $40 \mathrm{mg}$ ). $1 \mathrm{ml}$ of diethyl ester, 5 $\mathrm{ml}$ of methanol and $0.2 \mathrm{ml}$ of acetyl chloride were added to the residue and the flask was filled with nitrogen, and then it was boiled with the reflux condenser on the glycerin bath for $45 \mathrm{~min}$ at $70^{\circ} \mathrm{C}$. The solution obtained was evaporated in the nitrogen stream to a volume of $0.3 \mathrm{ml}$. Then $2 \mathrm{ml}$ of cyclohexane were added and stirred for $1 \mathrm{~min}$. After the complete stratification of the layers, the upper cyclohexane layer was used as a test sample. It was filtered through a filter with $0.2 \mathrm{~g}$ of sodium sulfate. The resulting solution was subjected to analysis by gas chromatography Shimadzu GC-14B, FID chromatography under the following conditions: capillary column $(60 \mathrm{~m} \times 0.32 \mathrm{~mm}$ HP-23; $0.25 \mu \mathrm{m}$ ), the column temperature was held at $175^{\circ} \mathrm{C}$ for $2 \mathrm{~min}$, and then raised to $225^{\circ} \mathrm{C}$ with a rate of $3^{\circ} \mathrm{C} / \mathrm{min}$, injector and detector temperatures were $240^{\circ} \mathrm{C}$ and $250^{\circ} \mathrm{C}$ respectively, the carrier gas flow rate (nitrogen) was $1.0 \mathrm{ml} / \mathrm{min}$, split ratio was $1: 60$. The content of each fatty acid was calculated by the internal regulation method (Kanaan et al., 2005).

\section{Determination of trace elements from Pterocladia}

Following tests were conducted in the Institute of Monocrystals, Kharkov, Ukrain. $2 \mathrm{~g}$ of Pterocladia powder were placed in a capillary tube of fluorized polymers in order to disperse them under pressure and microwaves. After adding $5 \mathrm{ml}$ of $\mathrm{HNO}_{3}(70 \%)$ the capillary was firmly closed and placed in a steam room for $20 \mathrm{~min}$, under a pressure not exceeding $120 \mathrm{psi}$. After cooling and filtration, the substance was recovered in a 50 $\mathrm{ml}$ tube filled with water, thereby obtaining liquid number $1.1 \mathrm{ml}$ was taken from liquid 1 and put it in a $100 \mathrm{ml}$ tube filled with water up to $100 \mathrm{ml}$ obtaining therefore liquid 2 (Kanaan et al., 2005).

In order to determine macro-elements percentages, a Thermo Jarrel Ash atomic absorption spectrometer was used.

Liquid 1 was used to determine the percentage of $\mathrm{Fe}, \mathrm{Zn}$, $\mathrm{Cu}, \mathrm{Ni}, \mathrm{Mn}, \mathrm{Al}$ and $\mathrm{Se}$.

Liquid 2 was used to determine the percentage of $\mathrm{Ca}$, $\mathrm{Mg}, \mathrm{K}$ and $\mathrm{Na}$.

Conditions: Liquid flow speed: $1.85 \mathrm{ml} / 1 \mathrm{mn} 2 \mathrm{sec}$

The flow speed of added Argon (Ar): $11 /$ min

The flow speed of initial Argon (Ar): $141 /$ min

\section{Evaluation of biological activities Antioxidant activity}

$20 \mathrm{ml}$ of tyrode solution $(\mathrm{NaCl} 137.0 \mathrm{mM}, \mathrm{KCl} 2.7 \mathrm{mM}$, $\mathrm{MgCl}_{2} 1.0 \mathrm{mM}, \mathrm{CaCl}_{2} 1.5 \mathrm{mM}, \mathrm{NaH}_{2} \mathrm{PO}_{4} 0.4 \mathrm{mM}, \mathrm{NaHCO}_{3} 12.0$ $\mathrm{mM})$ was introduced in a basin provided with two platinum electrodes maintained at a distance of $2 \mathrm{~cm}$ from each other, and connected by electric wires to an electrical stimulator delivering a current of $10 \mathrm{~mA}$ controlled by a digital multimeter. A cascade of free radicals will be as a result generated by electrolysis in the tyrode solution (Chahine et al., 1998).

A constant current of $10 \mathrm{~mA}$ generated by the stimulator was applied during $5 \mathrm{~min}$ in $20 \mathrm{ml}$ of physiological solution (tyrode) to generate free radical and their derivatives. We carried out the electrolysis of the tyrode solution in the absence of polysaccharides isolated (sulfated galactans or carrageenan) used as control and in the presence of different concentrations of these extracts $(0.15,0.3,0.6 \mathrm{~g} / \mathrm{l})$. At each minute of electrolysis a volume of $1 \mathrm{ml}$ of electrolyzed tyrode was added to $2 \mathrm{ml} \mathrm{N}, \mathrm{N}$ diethyl-p-phenylenedialanine (DPD) $(25 \mathrm{mg} / \mathrm{ml})$. Then the absorbance was determined by spectrophotometer at $515 \mathrm{~nm}$.

\section{Anticoagulant activity}

Activated partial thromboplastin time (APTT) assays were carried out by the method of Anderson et al. (1976). Normal human platelet-poor plasma $(100 \mu \mathrm{l})$ was incubated with $10 \mu \mathrm{l}$ of a solution of polysaccharide $(0.05,0.5,2.5,5.0 \mu \mathrm{g})$ at $37^{\circ} \mathrm{C}$ for 1 min. Then $100 \mu \mathrm{l}$ of APTT reagent (Human Gesellschaft, Germany) were added and incubated at $37^{\circ} \mathrm{C}$. After 2 min of incubation $100 \mu 1$ of $0.25 \mathrm{M} \mathrm{CaCl} 2$ were added to the mixtures and the clotting time was recorded on a coagulometer (Thrombotimer "Behnk elektronik").

\section{RESULTS AND DISCUSSION}

\section{Polysaccharides content of Pterocladia}

In enzymatic digestion using papain, the total yield of sulfated galactans extracted from $25 \mathrm{~g}$ of red algae Pterocladia collected at the Lebanese coast was $2.7 \%$. According to the literature and using the same extraction method, the content of sulfated galactans isolated from Botryocladia occidentalis collected at Brazilian coast was about $4 \%$ (Farias et al., 2000) and Pereira et al (2005) obtained a yield of $2.6 \%$ from the red alga Gelidium crinale. The differences in the sulfated galactans compositions of red algae are probably due to the fact that the specimens were collected at different sites, at different times and were different species (Marsham et al., 2007) and that the latter species seems to be richer in sulfated galactans.

Moreover, the content of carrageenan isolated from Pterocladia treated in distilled water at $90^{\circ} \mathrm{C}$ was about $11.5 \%$. According to Mouradi et al (2006), the content of carrageenan isolated from Hypnea musciformis treated at $80^{\circ} \mathrm{C}$ was $14.55 \%$ and $7.33 \%$. at $100^{\circ} \mathrm{C}$.

Thus, it appears that the yield of carrageenan at $90^{\circ} \mathrm{C}$ was satisfactory bearing in mind that the yield and quality of 
carrageenan depend on environmental factors and species (Mtolera et al., 2004; Marsham et al., 2007).

\section{Determination of fatty acids from Pterocladia}

The fatty acids detected in the algal sample were analyzed from the spectrum, their concentrations were determined and shown in Table 1. We noticed that the red algae Pterocladia was composed of $69 \%$ of saturated fatty acids, $31 \%$ of monounsaturated fatty acids and did not contain polyunsaturated fatty acids (Summarized in Table 1) The major fatty acid was palmitic acid $(53.749 \%)$ followed by the unsaturated vaccenic acid (14.485\%). The study of MacArtain et al (2007) showed that Porphyra and Palmaria spp contain respectively 64.95 and $60.48 \%$ saturated fatty acids, 18.91 and $10.67 \%$ monounsaturated fatty acids and 16.1 and $28.86 \%$ polyunsaturated fatty acids.

On the one hand, according to Norziah et al (2000) Changgi Gracilaria appeared to be rich in unsaturated fatty acids (74\%) especially omega 3 fatty acids (eicosapentaenoic acid 20:5 $\omega 3(33.1 \%)$, docosahexaenoic acid 22:6 $\omega 3(12.9 \%)$ that didn't appear in Pterocladia.

Its content in oleic acid $21.9 \%$ was higher than that present in our case $9.835 \%$. Like Pterocladia but with a lower rate, palmitic acid was the principal fatty acid (22\%). On the other hand, Pterocladia capillacea collected at the Egyptian coast contained high levels of polyunsaturated fatty acids (11\%): arachidonic acid omega-6 (10\%) and low omega-3 eicosapentaenoic acid (1\%). The most abundant fatty acids were oleic acid (55\%) and palmitic acid (31\%) (Wassef et al., 2002). This indicates that the composition of algae differs by place of collection and geographic area (Marsham et al., 2007).

\section{Determination of trace elements from Pterocladia}

The elements were detected in the algal sample and their concentrations were determined and summarized in table 2 .
Pterocladia appeared rich in $\mathrm{K}, \mathrm{Ca}, \mathrm{Si}, \mathrm{Mg}, \mathrm{Na}, \mathrm{P}, \mathrm{Fe}$ and $\mathrm{Zn}$. Each element is essential for the proper functioning of the body.

Therefore, it seems possible to use the algae to reduce high blood pressure due to its high concentration in $\mathrm{K}$ $(2220 \mathrm{mg} / 100 \mathrm{~g})$. Its high content of $\mathrm{Fe}(110 \mathrm{mg} / 100 \mathrm{~g})$ allows it to be used as food for people with syndrome of iron deficiency taking into account that the daily intake of $\mathrm{Fe}$ is $10 \mathrm{mg}$ per day for humans. The $\mathrm{Ca}$ and $\mathrm{Si}$ play a role in bone formation and connective tissue. $\mathrm{Zn}$ is an essential cofactor for certain enzymes. Detection of phosphorus can indicate the level of water pollution due to the long-term use of phosphate fertilizers. The seaweed is one of the best bio-accumulators of various elements; it could be used to study the environment where it grows (Bino Devi et al., 2011). The relatively low content of $\mathrm{Pb}, \mathrm{Hg}, \mathrm{Cd}$ and $\mathrm{As}$, even negligible, indicates that this alga is cultivated in an unpolluted environment.

As the red algae have not been studied previously in Lebanon, our results will be compared with various species of red algae collected from different countries. Thus, Pterocladia collected at the Lebanese coast appeared to be richer in calcium (740 mg/100g), Iron (110 mg/100g), Zinc (74 mg/100g) and copper $(3.7 \mathrm{mg} / 100 \mathrm{~g})$ than Changgi Gracilaria collected from Malaysia beach containing $651 \mathrm{mg} / 100 \mathrm{~g}$ of $\mathrm{Ca}, 95.6 \mathrm{mg} / 100 \mathrm{~g}$ of $\mathrm{Fe}, 13.8 \mathrm{mg} / 100 \mathrm{~g}$ of $\mathrm{Zn}$ and $0.8 \mathrm{mg} / 100 \mathrm{~g}$ of $\mathrm{Cu}$ (Norziah et al., 2000). According to MacArtain et al., 2007, the mineral composition of the three species of red algae collected from Asia: Porphyra umbilicalis, Palmaria palmata and Chondrus crispus comparing to Pterocladia is presented in Figure 1 below. The results showed that Pterocladia is richer in $\mathrm{Ca}, \mathrm{K}, \mathrm{Cu}, \mathrm{Fe}$ and $\mathrm{Zn}$ that these three species of red algae. While Chondrus crispus is the richest in $\mathrm{Mg}$ and $\mathrm{Na}$. Hence Pterocladia appears to be useful in the food industry as a source of highly nutritious ingredients.

Table. 1: Types of fatty acids contained in the red algae Pterocladia and their percentage concentration

\begin{tabular}{cllllll}
\hline Peak \# & \multicolumn{1}{c}{ Compound } & Common name & Retention Time & \multicolumn{1}{c}{ Area } & Height & Concentration (\%) \\
\hline 1 & C14:0 & Myristic acid & 7.594 & 19186 & 3655 & 6.982 \\
2 & C16:0 & Palmitic acid & 12.436 & 147703 & 29990 & $\mathbf{5 3 . 7 4 9}$ \\
3 & C16:1 n9 & Palmitoleic acid & 12.953 & 18336 & 4098 & 6.672 \\
4 & C18:0 & Stearic acid & 16.641 & 22744 & 4810 & 8.276 \\
5 & C18:1 n9 & oleic acid & 16.984 & 27027 & 5390 & 9.835 \\
6 & C18:1 n11 & vaccenic acid & 17.123 & 39806 & 8903 & 14.485 \\
total & & & & 274802 & 56846 & \\
\hline
\end{tabular}

Table. 2: Trace elements content of red algae Pterocladia and their concentrations ( $\mathrm{mg}$ of trace element $/ 100 \mathrm{~g}$ of algae)

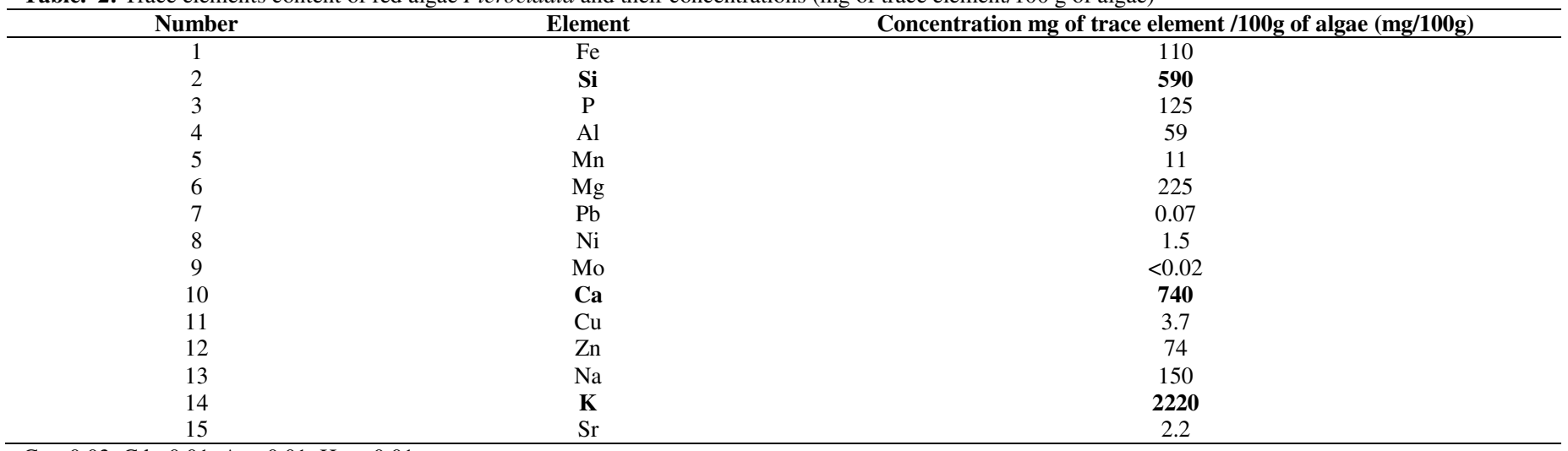




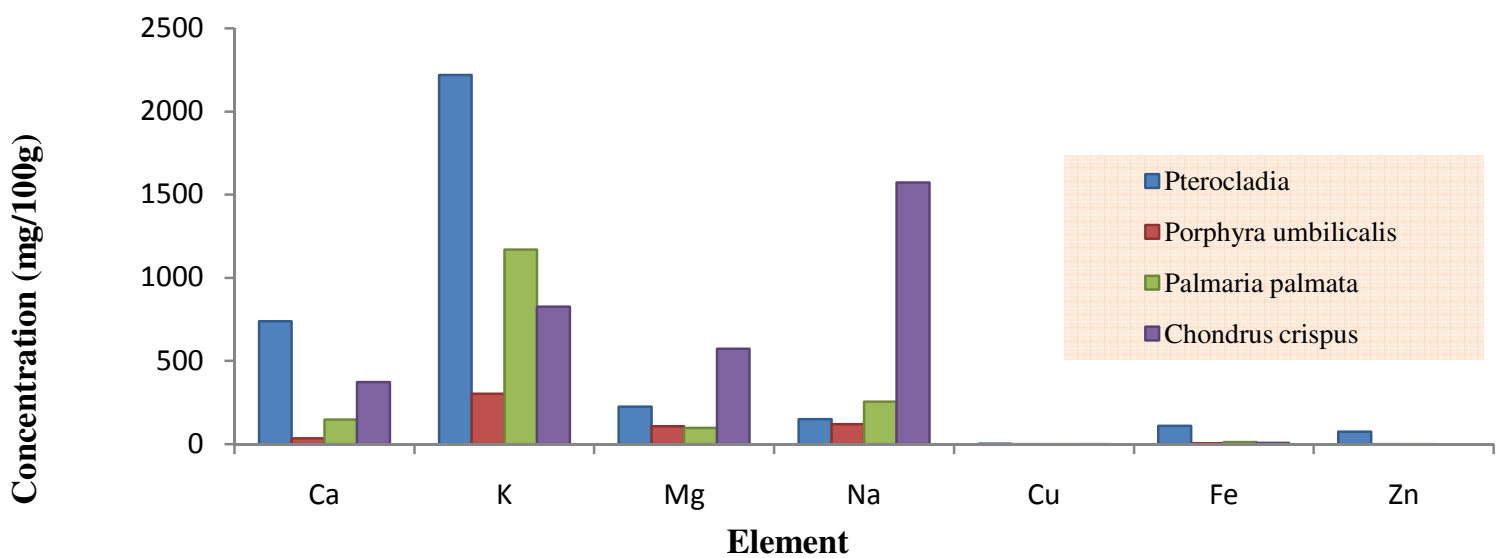

Fig. 1: Comparison of the mineral composition of Pterocladia with that of three species of red algae collected from the Asian coast (Porphyra umbilicalis, Palmaria palmate, Chondrus crispus). Concentration was expressed as $\mathrm{mg}$ of element / $100 \mathrm{~g}$ of alga.
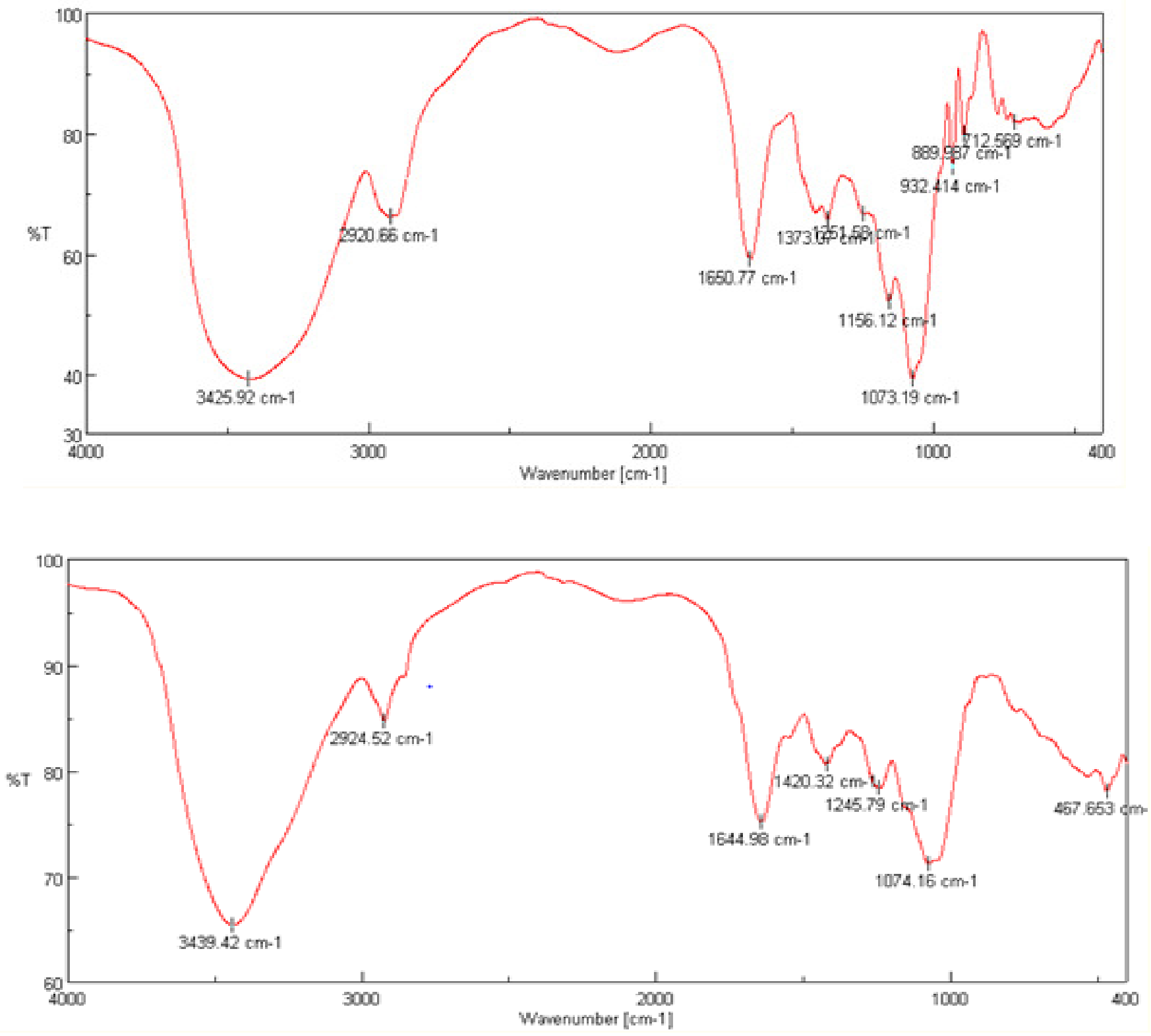

Fig. 2: Infrared spectrum of carrageenan(A) and sulfated galactans $(B)$ isolated from Pterocladia 


\section{Infrared analysis}

The carrageenan spectrum below (Fig. 2 A) shows a strong absorption band at $3425.92 \mathrm{~cm}^{-1}$ due to the stretching vibration of $v(\mathrm{O}-\mathrm{H})$, a band at $2920.66 \mathrm{~cm}^{-1}$ due to the vibration $v$ $(\mathrm{C}-\mathrm{H})$ and a band at $1650.77 \mathrm{~cm}^{-1}$ assigned to an asymmetric stretching vibration of O-C-O (Chopin et al., 1999). The absorption bands at 1373.07 and $1251.58 \mathrm{~cm}^{-1}$ correspond to the asymmetric stretching vibration of the ester sulphate (Chopin et al., 1999). The weak signal at $125.58 \mathrm{~cm}^{-1}$ is due to the elimination of the sulfate group leading to the formation of 3,6anhydrogalactose residue. The band located at $1156.12 \mathrm{~cm}^{-1}$ may be due to the stretching vibration of sulfate esters, $v(\mathrm{C}-\mathrm{O}-\mathrm{C})$ or $v$ (C-C). And one located at $1073.19 \mathrm{~cm}^{-1}$ is due to the symmetric stretching vibration of sulfate group SO (Chopin et al., 1999). The absorption band at $932.414 \mathrm{~cm}^{-1}$ is characteristic of the 3,6anhydrogalactose residue, that at $712.569 \mathrm{~cm}^{-1}$ appears to be characteristic of $\mathrm{C} 4$ galactose sulfate (COSO4) and the absorption band located at $889.987 \mathrm{~cm}^{-1}$ corresponds to the vibration $\delta(\mathrm{C}-\mathrm{H})$ glucoside. But the absence of the absorption band at $805 \mathrm{~cm}^{-1}$ characteristic of the 3,6-anhydrogalactose-2-sulfate residue indicates that this type of carrageenan does not match iotacarrageenan. In addition, this spectrum does not show the two absorption bands characteristic of the $\lambda$ carrageenan: a strong band at $830 \mathrm{~cm}^{-1}$ corresponding to the galactose-2-sulfate and a band at $820 \mathrm{~cm}^{-1}$ corresponding to the galactose 6-sulfate (Rochas et al., 1986). Thus the various peaks attributed above indicate that the studied carrageenan is probably of Kappa type.

The IR spectrum of sulfated galactans (Fig. 2 B) shows the same bands as those observed with carrageenan. But the characteristic absorption bands of the vibrations of the sulfate groups (at $1420.32,1245.79$ and $1074.16 \mathrm{~cm}^{-1}$ ) are of greater intensity than those observed with carrageenan. In addition, the absence of the band at $930 \mathrm{~cm}-1$ characteristic of the 3,6anhydrogalactose residue show that this polysaccharide has been esterified with numerous sulfate functions.

\section{${ }^{1}$ H N M R analysis reveals $\beta$ unit}

The ${ }^{1}$ H NMR analysis has become the tool most commonly used for characterization of carrageenans. The ${ }^{1} \mathrm{H}$ one dimensional spectra of carrageenan and sulfated galactans from Pterocladia are shown in Fig $3 \mathrm{~A}$ and B. These spectra reveal a triplet centered approximately at $1.05 \mathrm{ppm}$ corresponding to a proton methylene $\mathrm{CH} 2$ and a quadruplet at $3.55 \mathrm{ppm}$. This signal may be due either to the presence of $\mathrm{O}-\mathrm{CH} 3$ bond or is assigned to the $\beta$ unit (Farias et al., 2000). But these spectra do not show signals between 4.4 and $5.4 \mathrm{ppm}$ relative to the region of anomeric sugars (Praiboon et al., 2006) nor the signal at $5.2 \mathrm{ppm}$ corresponding to the unit $\alpha$ (Farias et al., 2000). This seems to be related to the temperature applied during the analysis and which should be set at around $65^{\circ} \mathrm{C}$ and even higher. In fact, temperature affects positively the viscosity reducing the height of the peaks and shifting the solvent resonance (Claudio et al., 2008). Hence, a higher resolution requires high temperature.
Antioxidant action of sulfated galactans and carrageenans from the red algae Pterocladia

We further investigate the antioxidant effects of the polysaccharides derived from the red algae Pterocladia by the electrolysis method. The electrolysis of the Tyrode solution generates between the cathode and the anode oxidizing species (free chlorine, hypochlorous acid, ROS). The latter react instantly with DPD reagent to reveal a red color whose intensity varies with the amount of ROS released as a function of time.

The graphs below (Fig 4) illustrate the antioxidant effect of carrageenan and sulfated galactans isolated from the red algae Pterocladia against oxygenated free radicals generated by electrolysis of a physiological medium. The present study showed a greater effect for sulfated galactans. Moreover, in the absence of these active compounds (control curve), the concentration of ROS increased gradually with time until reaching a maximum absorbance of 0.45 corresponding to a bright red color in the 5th minute of electrolysis (Fig 4). While for the same concentration of the initial solution used ( $3 \mathrm{~g} / \mathrm{l})$, we notice that as far as the concentration of the extracts (sulfated galactans or carrageenan) increases ranging from $0.15 \mathrm{~g} / 1$ to $0.6 \mathrm{~g} / 1$, the formation of ROS during the electrolysis is gradually attenuated comparing to the control curve (Fig 4), thus illustrating the power of these extracts to scavenge free radicals therefore their antioxidant effects. As well, we observed a decrease in the intensity of the color of the solution (the red color appeared less deep than in the absence of the extract) and a subsequent decrease in the absorbance over time compared to the control curves.

Furthermore, this study showed more pronounced antioxidant power of sulfated galactans which makes it depend on the composition and the degree of sulfation of the polysaccharide. Indeed, three fractions of sulfated polysaccharides isolated from Porphyra haitanesis which differ in the content of sulphates show that the fraction richest in sulphate has the strongest antioxidant effect (Zhang et al., 2003). Another study by Souza et al (2007) also showed a positive correlation between sulfate content and antioxidant activity which confirms our results. As well, the study of Yuan et al (2006) indicates that the chemical modification (oversulfated) of carrageenan oligosaccharides can enhance their antioxidant activity in vitro. We concluded that the richer the compound is in sulfate the higher is its antioxidant activity.

In order to confirm the greater effect of sulfated galactans, we calculated the percentage of inhibition of oxygenated free radicals by carrageenan and sulfated galactans (Fig. 5). At the 5th minute of electrolysis and at the highest concentration $0.6 \mathrm{~g} / 1$, the maximum absorbance for sulfated galactans and carrageenan was respectively 0.13 and 0.24 (Fig 4). For the control curve and in the absence of these two compounds the absorbance was 0.45 (Fig 4) which indicates $100 \%$ of inhibition. Thus, we obtain as the ability of these active ingredients to inhibit ROS $71 \%$ and $47 \%$ for sulfated galactans and carrageenans respectively (Fig. 5) indicating that the galactans rich in sulfates exhibit more pronounced antioxidant activity than carrageenan. 


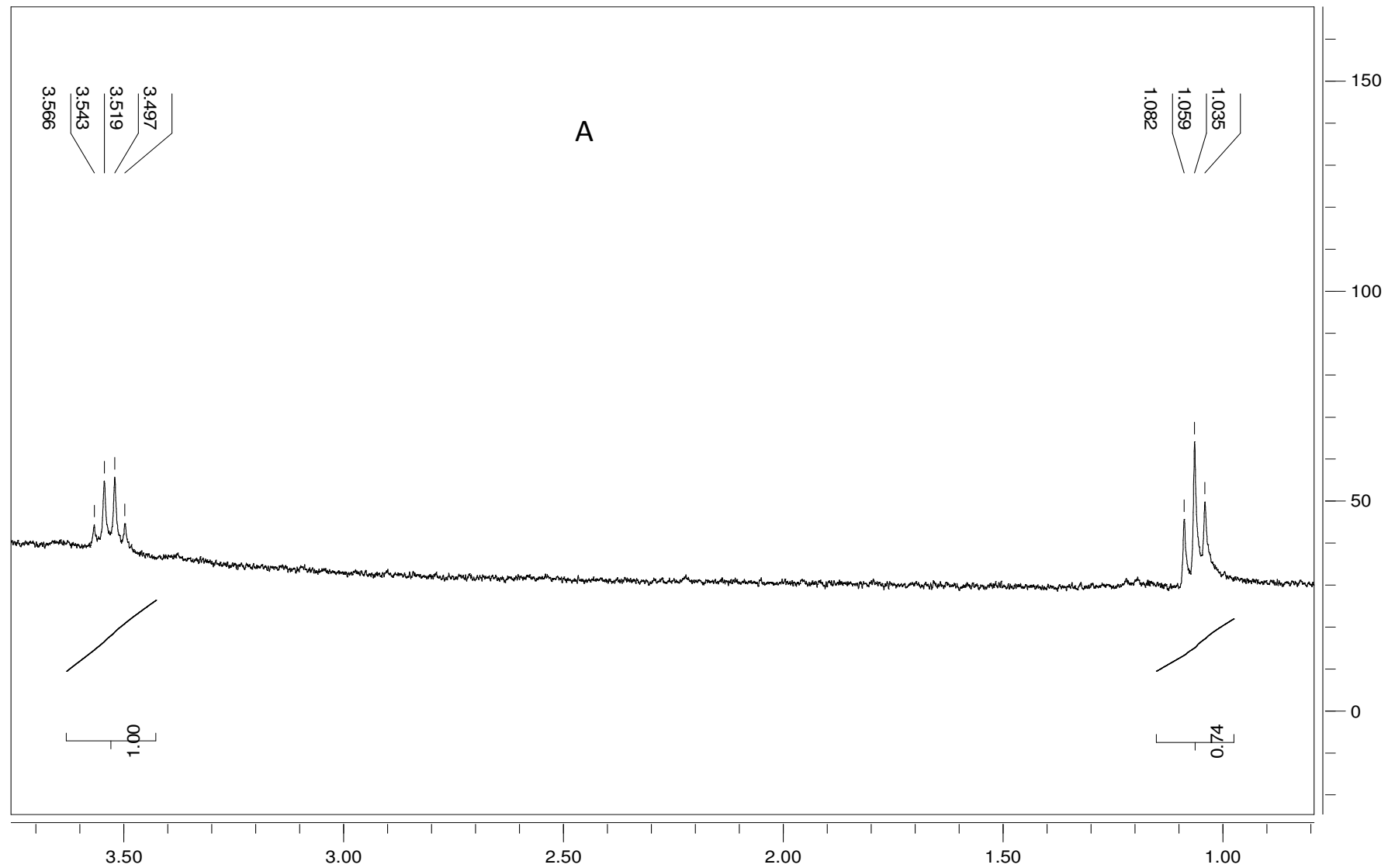

ppm (f1)

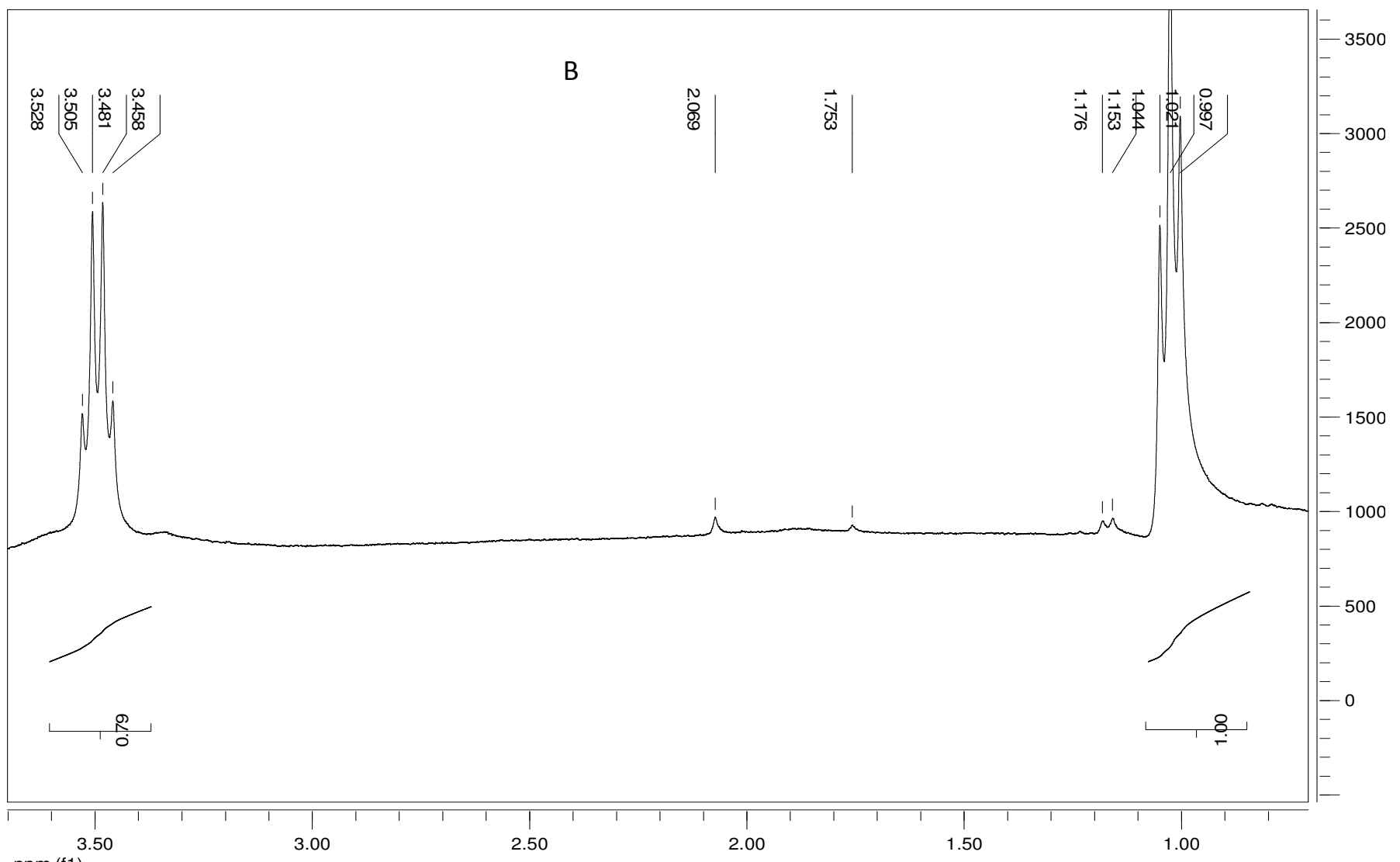

Fig 3: ${ }^{1}$ H NMR spectrum of carrageenan (A) and sulfated galactans (B) isolated from Pterocladia 

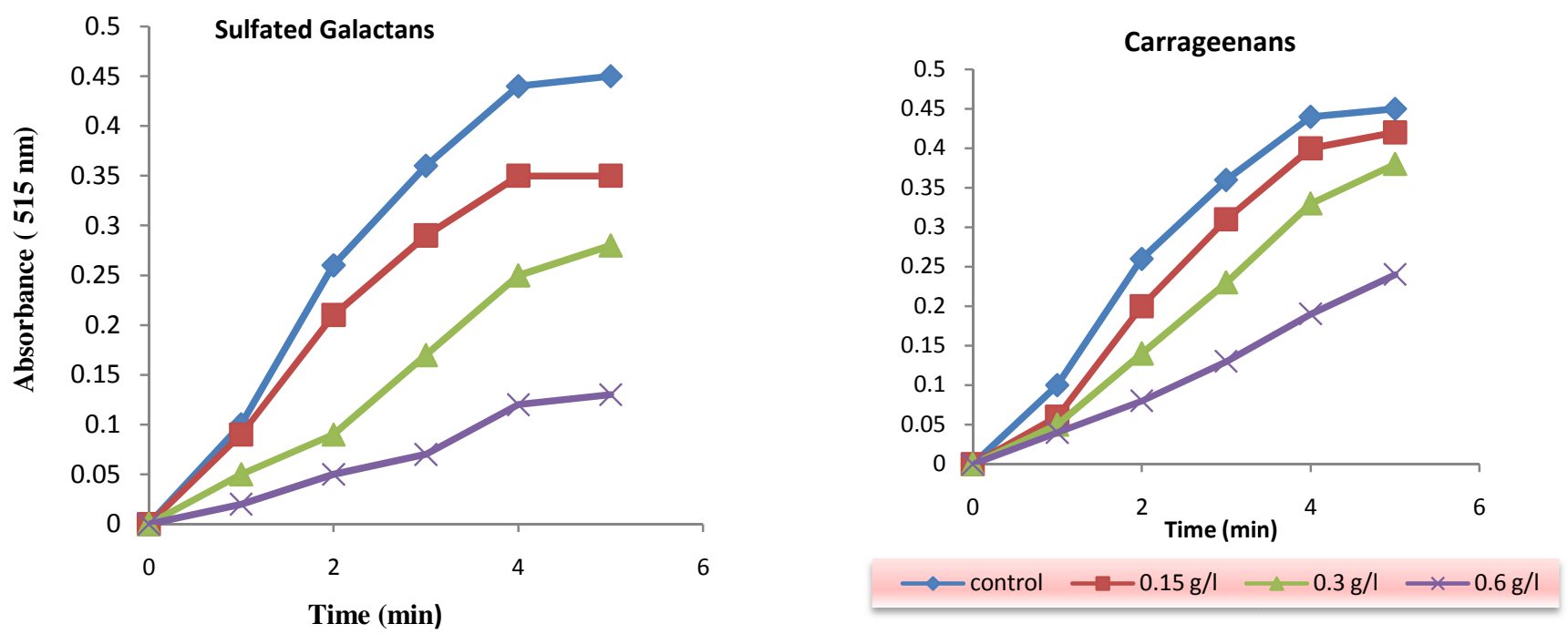

Fig 4: Antioxidant effect of sulfated Galactans and carrageenans isolated from Pterocladia. Different concentrations of these extracts $(0.15,0.3$ and $0.6 \mathrm{~g} / \mathrm{l})$ were added to the physiological solution after 5 min of electrolysis. (control = physiological solution alone).

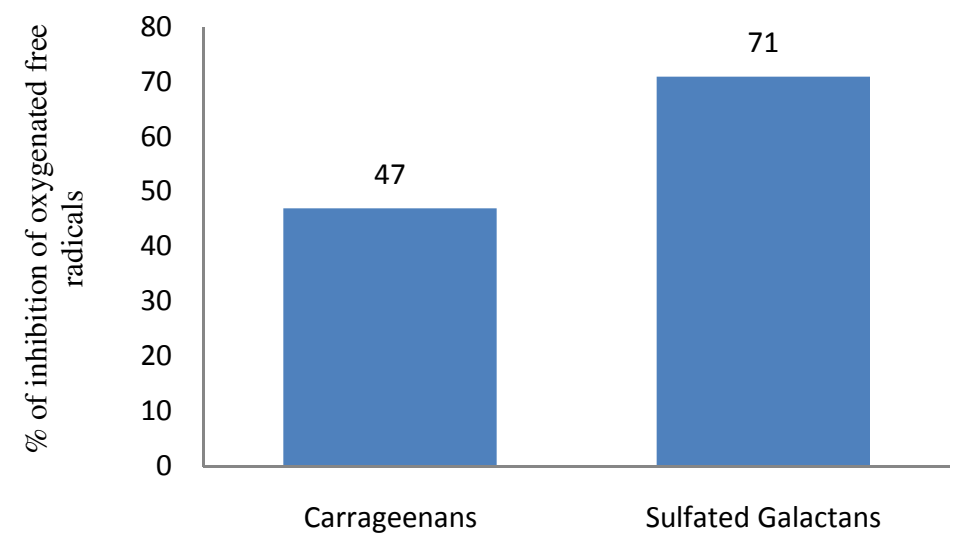

Fig 5: Inhibition of the oxygenated free radicals by carrageenans and sulfated galactans

Table. 3: Anticoagulant properties of sulfated polysaccharides derived from red algae Pterocladia.

\begin{tabular}{|c|c|c|c|}
\hline Polysaccharides & $\begin{array}{c}\text { Quantity } \\
(\mu \mathrm{g})\end{array}$ & $\begin{array}{c}\text { APTT } \\
\text { (s) }\end{array}$ & Ratio \\
\hline \multirow{3}{*}{ Carrageenan } & 0.05 & 38.0 & 1.27 \\
\hline & 0.5 & 39.5 & 1.32 \\
\hline & 2.5 & 39.9 & 1.33 \\
\hline \multirow{2}{*}{$\begin{array}{l}\text { Sulfated } \\
\text { Galactans }\end{array}$} & 0.05 & 37.6 & 1.25 \\
\hline & 0.5 & 38.7 & 1.29 \\
\hline
\end{tabular}

APTT was measured in second by a coagulometer. Ratio was calculated by the formula $:$ Ratio $=$ APTT measured $/$ APTT control $=$ APTT measured $/ 30$.

\section{Anticoagulant effect of Sulfated galactans and carrageenans from Pterocladia}

According to the literature, anticoagulant and antithrombotic activities are among the most widely studied properties of sulfated polysaccharides. Sulfated polysaccharides either extracted from marine brown (Cumashi et al., 2007) and red algae (Farias et al., 2000), or obtained by chemical sulfation of natural polysaccharides (Alban et al., 1995) have been described as anticoagulants. Therefore, it seems interesting to evaluate the anticoagulant activity of the polysaccharides isolated from Pterocladia. The APTT assay (summarized in Table 3) indicates that crude Pterocladia polysaccharides have anticoagulant action. 
After having measured the clotting time, the ratio was then calculated by the formula: ratio $=$ APTT/ Control $=$ APTT/ 30; knowing that the normal clotting time APTT is between 28-38 s, more precisely $30 \mathrm{~s}$ was taken as control. A significant anticoagulant effect was observed when the ratio was above 1.2. Thus, the results indicate that both carrageenans and sulfated galactans exhibit anticoagulant action at the lowest dose $0.05 \mu \mathrm{g}$ (Summarized in Table 3). Moreover, the data in Table 3 indicate that an increase in the quantity of polysaccharides from $0.05 \mu \mathrm{g}$ to $5 \mu \mathrm{g}$ induces an increase in the APTT. Thereby the ratio increases and the anticoagulant effect appears to be more pronounced.

We also noticed that sulfated galactans exhibit more powerful anticoagulant activity than carrageenans. For example, for the same dose of $2.5 \mu \mathrm{g}$ the ratio is 1.46 and 1.33 for galactans and carrageenan respectively. This ratio rises dramatically in the case of sulfated galactans to reach 2.03 for a dose of $5 \mu \mathrm{g}$ while that of carrageenan increases to 1.40 illustrating an anticoagulant power of galactans more pronounced (Table 3). This is justified by the fact that the sulfate content is important for the anticoagulant action (Farias et al., 2000; Shanmugam et al., 2000) and the interaction with antithrombin depends on the distribution of sulfate groups (position), the monosaccharide composition and the molecular weight of the compound (Melo et al., 2004) thereby the bulky structure of sulfated galactans is involved in its anticoagulant activity. Confirming this, $\mathrm{K}, \lambda$, i-carrageenan of high molecular weight and having a high content of sulfates exhibit an anticoagulant activity higher than that of low sulfate content and low molecular weight (Shanmugam et al., 2000).

On the other hand, the sulfated galactans extracted from Botryocladia occidentalis exhibit an APTT (130 IU / mg) compared with standard polysaccharides: heparin (193 IU / mg) and lambda carrageenan (77 IU / mg) (Farias et al., 2000). These results also showed greater effect of sulfated galactans in comparison with carrageenan. These same results are shown in the study of Melo et al (2004). A study of Silva et al (2010) shows that APTT for Kappa and iota carrageenan $(100 \mu \mathrm{g})$ was respectively 240 and $132 \mathrm{~s}$ and lambda carrageenan $(20 \mu \mathrm{g})$ was the most potentially anticoagulant 240 s. Our study may lead to such results if we continue to increase the dose and this can give us an idea about the type of carrageenan obtained.

\section{CONCLUSION}

Red algae are a major resource for economic and industrial development. In addition to their high nutritional value, they take great interest as a source of therapeutic substances. In summary, our results indicate that the red alga Pterocladia growing on the Lebanese coast appears to be useful in the food industry as a source of highly nutritious ingredients. On the other hand, this species contains polysaccharide-type compounds such as sulfated galactans and carrageenans that exhibit a broad spectrum of biological activity. Indeed, these algal polysaccharides have potent anticoagulant and antioxidant activities. Moreover, the study of the antioxidant effect by the electrolysis method showed a greater effect for sulfated galactans. Furthermore, the study of the anticoagulant effect by APTT test, activated partial thromboplastin clotting assays, showed more pronounced anticoagulant power of sulfated galactans. A plausible reason for the greater antioxidant and anticoagulant effects of the sulfated galactans is its high sulfate groups compared with carrageenan.

Other surveys may be conducted in the future on this type of algae covering the extraction of the active ingredients, the possibility of formulating drugs from these products and the study of other therapeutic activities particularly antiviral or anti-tumor activity. New compounds with obvious practical applications may be found. Thus we can also test the carrageenan as lubricant to facilitate movements of the joints due to its ability to form a gel. Finally the sulfated galactans and carrageenans isolated from Pterocladia are natural candidate molecules for testing in experimental thrombosis.

\section{ACKNOWLEDGEMENTS}

We are grateful to the head of the National Council for Scientific research in Lebanon and to the Rector of the Lebanese University, Dean of the Doctoral School of Science and Technology, for their financial support to the research program.

\section{REFERENCES}

Alban S., Jeske W., Welzel D., Franz G., Fareed J. Anticoagulant and antithrombotic actions of a semisynthetic $\beta$-1,3-glucan sulfate Thromb. Res. 1995; 78: 201-210.

Anderson L.O., Barrowcliffe T.W., Holmer E., Johnson E. A., Sims G.E.C. Anticoagulant properties of heparin fractionated by affinity chromatography on matrix-bound antitrombin III and gelfiltrations. Thromb. Res. 1976; 9: 575-580.

Bino Devi Ch., Sharat Singh N.K., Rajmuhon Singh N., Rajendro Singh N., Sudarshan M., Chakraborty A., Ram S.S. Trace elements in nungsham, the red edible algae of Manipur. International journal of applied biology and pharmaceutical technology. 2011; 2: 09764550

Bottalico A., Foglie C.I.D., Fanelli M. Growth and reproductive phenology of Pterocladiella capillacea (Rhodophyta: Gelidiales) from the southern Adriatic Sea. Botanica Marina. 2008; 51: 124-131.

Chahine R., Feng J. Protective effects of taurine against oxidative stress. Arzneim-Forsch/Drug Res. 1998; 48: 360-364.

Chopin T., Kerin B.F., Mazerolle R. Phycocolloid chemistry as a taxonomic indicator of phylogeny in the Gigartinales, Rhodophyceae: a review and current developments using Fourier transform infrared diffuse reflectance spectroscopy. Phycol. Res. 1999; 47: 167-188.

Claudio S., Coppetta D., Giuseppe Basta S.S., Montanucci P., Racanicchi L., Calafiore R. NMR analysis of non hydrolysed samples of sodium alginate. $12^{\text {th }}$ international electronic conference on synthetic organic chemistry. 2008.

Cosson J., Deslandes E., Zinoun M., Mouradi-Givernaud A. Carrageenans and agars, read algal polysaccharide. Phycoclogical Research Eds. 1995 ; 11: 269-325.

Costa L.S., Fidelis G.P., Cordeiro S.L., Oliveira R.M., Sabry D.A., Câmara R.B.G., Nobre L.T.D.B., Costa M.S.S.P., Almeida-Lima J., Farias E.H.C., Leite E.L., Rocha H.A.O. Biological activities of sulfated polysaccharides from tropical seaweeds. Biomedicine \& Pharmacotherapy. 2010; 64: 21-28.

Cumashi A., Ushakova N.A., Preobrazhenskaya M.E., D’Incecco A., Piccoli A., Totani L., Tinari N., Morozevich G.E., Berman A.E., Bilan M.I. A comparative study of the anti-inflammatory, 
anticoagulant, antiangiogenic, and antiadhesive activities of nine different fucoidans from brown seaweeds. Glycobiology. 2007; 17: 541-552.

Delattre C., Fenoradosoa T.A., Michaud P. Galactans: An Overview of their Most Important Sourcing and Applications as Natural polysaccharides. Brazilian archives of biology and technology. 2011; 54: 1075-1092.

Estevez J., Ciancia M., Cerezo A. The system of galactans of the red seaweed, Kappaphycus alvarezii, with emphasis on its minor constituents. Carbohydrate Research. 2004; 339: 2575-2592.

Farias W., Valente A.P., Pereira M., Mourão, P. Structure and Anticoagulant Activity of Sulfated Galactans. The Journal of Biological Chemistry. 2000; 275: 29299-29307.

Guven K. C., Guler G., Aktin, E. In Marine Algae in Pharmaceutical Science (eds Hoppe, H. A., Lerving, T,Tanaka, Y). 1982. Walter de Gruyter, Berlin, pp. 693-710.

Kanaan H., Krivorushko E.B., Makhlouf H., Yassine A., Murtada, M. Trace elements and lipids in Padina pavonica in Lebanon. Arab Journal of pharmaceutical Sciences. 2005; 10: 21-28.

MacArtain P., Gill C.I.R, Brooks M., Campbell R., Rowland I.R. Nutritional Value of Edible Seaweeds. Nutrition Reviews. 2007; 65: 535-543.

Madhusudan C., Manoj S., Rahul K., Rishi, C. M. Seaweeds: a diet with nutritional, medicinal and industrial value. Res. J. Med. Plant. 2011; 5: 153-157.

Marsham S., Scott G.W., Tobin M.L. Comparison of nutritive chemistry of a range of temperate seaweeds. Food Chem. 2007; 100: $1331-1336$

Melo, F.R., Pereira, M.S., Foguel, D., and Mourão ,P.A. Antithrombin-mediated anticoagulant activity of sulfated polysaccharides. J Biol Chem. 2004; 279: 20824-35, No 20.

Mouradi A., Chikhaoui-khay M., Akki S., Akallal R., Hrrimlr I., Givernaud, T. Analyse structurale des fractions polysaccharidiques extraites de la paroi cellulaire d'Hypnea musciformis. Afrique Science. 2006; 2: 226-244.

Mtolera M.S.P., Buriyo, A.S. Studies on Tanzanian Hypneaceae: Seasonal Variation in Content and Quality of K-Carrageenan from Hypnea musciformis Western Indian Ocean. J. Mar. Sci. 2004; 3: 4349.

Norziah M.H., Ching C.Y. Nutritional composition of edible seaweed Gracilaria changgi. Food Chemistry. 2000; 68: 69-76.

Pereira M.G., Benevides N.M.B., Melo M.R.S., Valente A.P., Melo F.R., Mourão P.A.S. Structure and anticoagulant activity of a sulfated galactan from the red alga, Gelidium crinale. Is there a specific structural requirement for the anticoagulant action? Carbohydrate Research. 2005; 340: 2015-2023.

Pérez R. Ces algues qui nous entourent. In: S. Arbault, O. Barbaroux, P. Phliponeau, C. Rouxel (eds.). Aquaculture. Editions IFREMER, Plouzané, France. 1997. pp. 65-178.

Praiboon J., Chirapart A., Akakabe Y., Bhumibhamond O., Kajiwarac T. Physical and Chemical Characterization of Agar Polysaccharides extracted from the Thai and Japanese Species of Gracilaria. Science Asia. 2006; 32: 11-17.
Rochas C., Lahaye M., Yaphe W. Sulfate content of carrageenan and agar determined by infrared spectroscopy. Botanica Marina. 1986; 9: 335-340.

Shanmugam M., Mody K. H. Heparinoid-active sulphated polysaccharides from marine algae as potential blood anticoagulant agents. Current Science. 2000; 79: 1672-1681, No.12.

Silva F.R.F., Dore C.M.P.G., Marques C.T., Nascimento M.S., Benevides N.M.B., Rocha H.A.O., Chavante S.F., Leite, E.L. Anticoagulant activity, paw edema and pleurisy induced carrageenan: Action of major types of commercial carrageenans. Carbohydrate Polymers. 2010; 79: 26-33

Silva L.M.C.M., Lima V., Holanda M.L., Pinheiro P.G., Rodrigues J.A.G., Lima M.E.P., Benevides N.M.B. Antinociceptive and Anti-inflammatory Activities of Lectin from Marine Red Alga Pterocladiella capillacea. Biol. Pharm. Bull. 2010; 33: 830-835.

Souza M.C.R., Marques C.T., Dore C.M.P.G., Silva F.R.F., Rocha H.A.O., Leite E.L. Antioxidant, cytotoxic and hemolytic effects of sulfated galactans from edible red alga Hypnea musciformis. J Appl Phycol. 2007; 19: 153-160.

Trinchero J., Ponce N.M., Cordoba O.L., Flores M.L., Pampuro S., Stortz C.A., Salomon H., Turk G. Antiretroviral activity of fucoidans extracted from the brown seaweed Adenocystis utricularis. Phytother Res. 2009; 23: 707-712.

Wassef E.A., El Sayed A.M., Kandeel K.M., Mansour H.A., Sakr E.M. Effect of Feeding Pterocladia and Ulva meals in diets for gilthead bream Sparus aurata. Cahiers Options Méditerranéennes, 63 and Paper presented at the 10th International Symposium on Nutrition and Feeding in Fish, Rhodes(Greece) 2002; p.28.

Whitfield F.B., Helidoniotis F., Shaw K.J., Svoronos, D. Distribution of bromophenols in species of marine algae from eastern Australia .Agric Food Chem. 1999; 47: 2367-73.

Yuan H., Song J., Li X., Dai J. Immunomodulation and antitumor activity of $\kappa$-carrageenan oligosaccharides. Cancer letters. 2006; 243: 228-234

Yuan H., Song J., Zhang W., Li X., Li N., Gao X. Antioxidant activity and cytoprotective effect of $\kappa$-carrageenan oligosaccharides and their different derivatives. Bioorganic \& Medicinal Chemistry Letters. 2006 ; 16: 1329-1334.

Zhang Q., Yu P., Li Z., Zhang H., Xu Z., Li, P. Antioxidant activities of sulfated polysaccharide fractions from Porphyra haitanesis. Journal of applied phycology. 2003; 15: 305-310.

\section{How to cite this article:}

C. Sebaaly, N. Karaki, N. Chahine A. Evidente A. yassine, J. Habib and H. Kanaan. Polysaccharides of the red algae "Pterocladia" growing on the Lebanese coast: Isolation, structural features with antioxidant and anticoagulant activities . J App Pharm Sci. 2012; 2 (10): 001-010. 